\title{
The Derivational Theory of Legal Interpretation in Polish Legal Theory
}

\author{
Olgierd Bogucki ${ }^{1}$
}

Published online: 18 June 2019

(c) The Author(s) 2019

\begin{abstract}
The article presents so-called "derivational" theory of legal interpretation and analyzes its basic assumptions. The derivational theory of legal interpretation is still little known outside of Poland (in contrast to the clarificative theory which was popularized in many English-language publications by Jerzy Wróblewski). The article is divided into two parts. The first part is presenting the normative model of legal interpretation according to the derivational theory. In the second part, the basic assumptions and features of the theory are analysed in context of some other approaches to legal interpretation. The author argues that there are two levels (or aspects) of the derivational theory: local and universal. The local level of theory is related to the fact that it was designed for Polish legal system and legal culture. However, beyond its local features, the derivational theory is presenting strong theoretical framework and some significant universal ideas about legal interpretation. This creates universal level that can be called the "hard core" of the theory. The author characterizes the elements of this hard core, and in particular the most important element: the idea that the legal interpretation consists in the reconstruction of legal norms from legal provisions.
\end{abstract}

Keywords Legal interpretation · Theory of law $\cdot$ Philosophy of law $\cdot$ Derivational theory of legal interpretation

\section{Introduction}

Polish legal theory developed so-called "derivational" theory of legal interpretation which is normative theory ${ }^{1}$ offering holistic interpretive procedure (set of interpretive directives). The derivational theory of legal interpretation was developed by

\footnotetext{
${ }^{1}$ It is about how we should interpret and not about how the people (the judges) usually interpret the legal text.

Olgierd Bogucki

olgierd.bogucki@usz.edu.pl

1 University of Szczecin, Al. Papieża Jana Pawła II 22a, 70-453 Szczecin, Poland
} 
Zieliński [35-38], but it was also expanded and improved by other authors as well [see for example: $1,5,6,15,16$ ]. The derivational theory of legal interpretation is still little known outside of Poland (in contrast to Wróblewski's clarificative theory of legal interpretation). Therefore one of the aims of this article is just to present it. The second one is to put it in the context of contemporary international (Englishlanguage) discussion about legal interpretation and discuss some crucial assumptions of the theory. The article is divided into two parts. The first part will present the process of legal interpretation according to the derivational theory. In the second part, I will discuss the basic assumptions and features of the theory in relation to some well-known approaches to legal interpretation. This, in turn, will allow to point out the advantages of the discussed theory and its "hard-core".

\section{The Process of Legal Interpretation}

\subsection{Basics}

First of all, it should be emphasized that the derivational theory is highly developed and concerns many detailed issues. The theory offers about one hundred and fifty detailed directives and it is difficult to present them all. For this reason, I will confine myself to presenting a general outline of the theory.

The derivational theory is based on a conceptual distinction between a legal provision (legal disposition) and a legal norm (proposed by Ziembiński [39]). According to the derivational theory, legal interpretation is a process of reconstructing (deriving) legal norm from legal provisions. The legal provision is defined as the basic unit of legal texts, being a sentence from a grammatical point of view, and a legal norm is a norm of conduct that has strictly defined syntactic structure: (order or prohibition)-(addressee)-(given situation)-(given conduct). In other words, a legal norm is an order or a prohibition of conduct for the given addressee in a given situation, which is sufficiently unequivocal.

If we examine the wording of the provisions we will see that they are not simply norms. In many cases their wording differs (sometimes much) from the model structure of the norm. Different provisions contain different elements of the norm, so the task of the interpreter is to "translate" set of provisions into the legal norm. According to Zieliński example, if we want to reconstruct a norm prohibiting killing from the text of the Polish Penal Code we can not just stop at Article $148 \S 1$ (establishing the crime of intentional killing), but we have to take into account all relevant legal provisions as well [35]. In doing so, we can reconstruct the norm of content: "A person, who is not a mother acting under influence of the childbed and during it, and who is not a person which in necessary defence is repelling any direct and illegal attack against any social good or any personal good, and who is not an authorised person executing a legally valid death penalty, and who is not a soldier acting against the enemy during the war hostilities (not in a way inconsistent with the laws of war), is ordered, in any circumstances, not to kill, and even not attempt to kill a man". 
According to the derivational theory interpretation of legal text is sequential and consists of three phases of interpretation.

\subsection{The Arranging Phase of Interpretation}

First one is the arranging phase. Interpreter has to identify the content of the current legal text at the interpretational moment. It is worth to emphasize the distinction between the moment of interpretation and the interpretational moment [38: 316]. The first one is the moment in time in which interpreting activity is undertaken, the second one is the moment in time for which the outcome of the interpretation is determined. Usually these two moments overlap, but when we want to reconstruct a norm which was binding in some moment in the past (in relation to the moment of interpretation) - they are separated in time. Determining the moment of interpretation determines the set of provisions that should be taken into account. In the arranging phase interpreter has to deal with problems caused by the change of legal provisions (their derogations or amendments) and take into account the repealing provisions and provisions changing wording of other provisions, so he is able to identify the set of binding legal provisions at given interpretational moment. It is worth to add that from the practical point of view we are talking about the set of legal provisions relevant to the given interpretative process (not the set of all valid legal provisions).

\subsection{The Reconstruction Phase of Interpretation}

The reconstruction phase is the second phase of interpretation. The interpreter of the legal texts has to reconstruct from all relevant legal provisions so called "normshaped expression". Norm-shaped expression is the utterance that has a structure of a legal norm (four elements: the normative operator of ordering or forbidding, the addressee, the circumstances and the determination of conduct). In this phase we have to take into account that legal norms are encoded by the lawmaker by using legislative technique of condensation and technique of dismemberment [38: 97-138]. The technique of condensation occurs when one legal provision contains some element (for example - the addressee) of more than one legal norm. On the other hand, the technique of dismemberment occurs when elements of one legal norm are separated and placed into different legal provisions.

According to the derivational theory, reconstructing norm-shaped expression starts from finding so called "the framework provision" that includes at least two elements of norm which are: an order or prohibition and the determination of conduct [38: 111]. If there are no other elements (the addressee and/or the circumstances) in the framework provision, the interpreter has to find them in other relevant provisions (called "supplementary provisions"). After that (or when there are all elements of norm in framework provision) the interpreter should check if there are any modifications of the elements of the norm contained in other provisions (called "modifying provisions"). When there are modifications, it is necessary to include them and formulate full norm-shaped expression. 
It is very important to emphasize that in Polish legal texts legal provisions are very often formulated in descriptive (not normative) manner. For example mentioned Article $148 \S 1$ of the Polish Penal Code (establishing the crime of intentional killing) was formulated as follows: "Who kills a man is penalised by no less than 8 years of imprisonment or by capital punishment" (wording valid from January 1970 until September 1998). As we can see there is no normative operator of ordering (or forbidding), so the interpreter has to add it himself. This is because of a general assumption of normativity of the legal text [38: 105]. According to the derivational theory, even if legal provision is formulated in descriptive manner we should treat it like it is expressing an order or prohibition.

\subsection{The Perceptual Phase of Interpretation}

The task of the interpreter in the third and final phase (the perceptual phase) is to make a norm-shaped expression a univocal expression (final outcome-norm of conduct). In this phase the interpreter should assign one meaning to each word (or chain of words) included in norm-shaped expression (to establish a norm). According to the derivational theory the process of finding the right meaning ought to be directed by two types of directives_-linguistic and extra-linguistic [38: 235].

The linguistic directives recourse to the rules of the language in which the legal text is written. The most important (and the first in the order of use) are the rules based on the legal definitions. That claim is based on the assumption that the meaning of a given word assigned by the legislator ought to be taken into consideration at the first place.

If there is no legal definition, or definition is ambiguous, the interpreter shall apply further directives. The next one is the directive that is ordering the interpreter to apply the meaning that has been established in a binding legal decision (ruling of the higher court). If there is no such decision the interpreter has to search for the meaning in the legal language (language of jurisprudence and judicial decisions). But if there is the meaning unanimously accepted by jurisprudence and judicial decisions this is the binding one for the interpreter. Otherwise he has to look for the meaning of the word (or the chain of words) in Polish language dictionaries. If there is only one meaning of the word in Polish language it is binding one for the interpreter. Otherwise he has to take into considerations all dictionary meanings and choose the one based on the linguistic context of the word (or chain of words) used in the text of a given legal act.

The above criteria are used to obtain the result of applying linguistic directives. However, their use may not be effective and there may still be more than one acceptable meaning. Taking this into account, we can therefore deal with two kinds of situations. The first one-there is a conclusion based on the linguistic directives; the second one-despite the use of linguistic directives we are not able to point out one right meaning.

According to the derivational theory of legal interpretation in both mentioned situations the interpreter should apply the extra-linguistic directives of interpretation (the systemic directives and the functional directives [38: 238]). In the first 
situation - to confront the result of applying linguistic directives with the result of applying the extra-linguistic directives. In the second one-to provide the one result of interpretation.

Application of the systemic directives aims to eliminate interpretation outcomes leading to inconsistency in legal system. The interpreter should eliminate any meaning of the interpreted word (or the chain of words) which leads to incompatibility with any norm from a higher level in legal system (like for example EU norms or constitutional norms) or with norm-principles of law.

The functional directives serve to achieve the result of the interpretation that has the best justification from the axiological and epistemological point of view. Recently, a detailed normative model has been developed showing how to achieve mentioned result [1]. According to this model the interpreter should reconstruct the "global assessment" (the comprehensive axiological judgement that consider all relevant values) and choose the one possible result of interpretation (the one norm of conduct) which will be the most consistent with this judgment. The comprehensive judgment can be understood as a set of values with the indicated degree of their realization. One of these values is the main value in the sense that a given norm has been established in order to implement it (this value can be called "the purpose of the norm"). It should be added that this comprehensive judgement is assigned to the rational legislator which is some kind of conceptual design (not real persons-members of the legislative body).

In order to reconstruct mentioned global assessment the interpreter should consider relevant interpretative sources which are: legal text, jurisprudence and judicial decisions, legislative materials. The use of these sources is recommended on the base of subsidiarity: the interpreter should consider the texts made by jurisprudence and judicial decisions only if the legal text is not capable to provide intersubjective conclusion and as well-he should move to the legislative materials only if jurisprudence and judicial decisions is not capable to provide intersubjective answer. According to this model, when there is still no conclusive result the interpreter should use the interpretive presumptions (in particular in dubio pro libertate-when there are impossible to resolve doubts we should conclude in favor of civil rights and freedoms or in favor of freedom from duty).

It should be noted that according to the derivational theory when there is a conflict between the result of applying linguistic directives and the result of applying extra-linguistic directives the interpreter should choose the first one unless there is extraordinary situation. The extraordinary situation is that the result of applying linguistic directives is unacceptable from the point of view of the basic values attributed to the rational lawgiver (like those expressed in the Constitution). However, there are some detailed restrictions like for example: the interpreter is not allowed to reject the univocal legal definition and accept the result of extra-linguistic interpretation [38: 343-344]. 


\subsection{Omnia Sunt Interpretanda}

It is very important to emphasize one crucial feature of the derivational theory of legal interpretation. This theory introduces the principle omnia sunt interpretanda as the basic principle of legal interpretation [38: 60]. According to this principle the interpretation of legal text (every legal provision) is always necessary, even if at the first look this text may seem to be clear. So we must always conduct the whole process of interpretation and not stop at the direct understanding of legal text (understanding prima facie - without reflective consideration). It needs to be highlighted that this approach is exactly the opposite of that accepted in the clarificative theory of legal interpretation (earlier and still influential theory of legal interpretation developed in Polish legal theory by Wróblewski). According to this theory clara non sunt interpretanda - it is not allowed to interpret clear provisions [34: 55-59].

The clarificative theory of legal interpretation was making sharp distinction between the direct understanding and the interpretation of legal text. The first one is when (briefly speaking) the interpreter has no doubts about meaning of legal text. The second one is when the interpreter has doubts about the meaning of legal text and apply interpretative directives to remove these doubts. According to the clara non sunt interpretanda principle when there is the situation of the direct understanding we should stop at this understanding. Zieliński was the one who strongly criticized the clara non sunt interpretanda and he formulated many arguments against such an approach [38: 53-61]. These arguments can be divided into several types like: epistemological, ethical, empirical, historical and pragmatic arguments as well. Since these arguments are difficult to fully discuss here, we can just limit ourselves to present the main theoretical idea underlying them. It seems very questionable whether direct understanding is possible at all without any interpretation and even if it is, the clara non sunt interpretanda could be dangerous for the objectivity (at least-the intersubjectivity) of legal interpretation.

If the interpreter should not even start interpretation when he has no subjective doubts about meaning, then understanding of the legal text is very strongly dependent on the subjective knowledge of the language and the surrounding world. That may even cause some kind of interpretive opportunism by granting the authority (for example the judge applying law) enormous discretionary power. The appeal to clara non sunt interpretanda can even allow the judges to exclude the interpretive dispute and to justify the legal interpretive decision by ratione imperii, instead of imperio rationis. On the other hand, if the clara non sunt interpretanda refers to the objective doubts, then it seems like the interpretation is the only way to make sure that there are no interpretive doubts. That is why the derivational theory introduced the omnia sunt interpretanda principle. It should be also added that there is still some discussion about the clara non sunt interpretanda principle because the supporters of the principle are trying to reformulate it to avoid presented critique. ${ }^{2}$

\footnotetext{
${ }^{2}$ See for example ,institutional" version of the clarity of a legal text by Marek Zirk-Sadowski [40: 156159]. The author points out that we can understand the concept of direct understanding in terms of the institutional explanation of the meaning of legal provisions in the constant and stable line of jurisdiction. See also arguments by Lech Morawski [24: 50-52] and Krzystof Płeszka [25: 195-235].
} 


\section{The Derivational Theory of Legal Interpretation versus Some Other Approaches}

\subsection{General Remarks}

Undoubtedly, the derivational theory of legal interpretation was formed on the background of Polish legal system, paradigm of legal positivism and tradition of Polish analytical philosophy. The determinants of the interpretative directives consists most of all: features of Polish legal texts and Polish legal culture. However, the theory offers good ideas and strong theoretical framework that may be the basis for different normative models of interpretation that fits different legal systems ${ }^{3}$ (and this is not only limited to statutory law).

There are many philosophical and theoretical assumptions underlying the discussed theory. In the following part I will try to discuss them in the context of the other views on legal interpretation.

\subsection{Conservation or Creativity? Rational Lawgiver and Legal Positivism}

Number of scholars distinguish two aspects or elements in interpretation: the conserving one and the creative one [10, 14, 23, 27, 28]. Different approaches ascribe different weight to these elements. For example, originalism claims that in interpreting a particular provision of the United States Constitution, judges should seek to establish the way in which the provision was originally understood by those who ratified it [2]. On the other hand, Levinson contends that all US constitutional interpretation is necessarily creative, due to radical and pervasive linguistic indeterminacy in the law [21].

The controversy indicated above does not apply directly to the derivational theory as long until we clarify the concept of creativity. "Creativeness" does not mean much until we indicate in relation to what something is to be creative. In the context of interpretation we can say for example that certain pragmatic meaning assigned by the interpreter is creative in relation to semantic meaning of the utterance. If we define "creativity" as a creation in relation to the meaning intended by persons who have established a given legal act, then the interpretation made in accordance with the derivational theory will sometimes be creative and sometimes not. It depends on how well these persons followed the rules of language, instrumental rationality and the values manifested in law. However, the derivational theory defines the purpose of interpretation as "the reconstruction of the norms established by the rational lawgiver-the law itself". From this perspective, no interpretation is creative even if it deviates from the intentions of members of the legislature or the semantic meaning of expression. The result of applying derivational theory is by definition a norm established by a rational legislator. However, a rational legislator is not a person of flesh and blood but a certain conceptual construction which consists of assumptions

\footnotetext{
3 About the possibility of applying the derivational theory to European Union law see Godek [15, 16].
} 
attributing to him specific features, such as full knowledge of the rules of language, full knowledge of the legal system and regulated field, instrumental rationality, implementation of socially accepted values expressed in law. He is the embodiment of the best knowledge and values of the interpretive community. It can be said that he is something like a positivist counterpart of Dworkinian Hercules. The concept of a rational lawgiver allows the derivational theory to preserve the basic positivist assumption (that the law comes from the lawgiver) and at the same time, incorporate the knowledge and values of the interpretive community into the interpretation.

At the first look, the juxtaposition of the Dworkin's theory with the derivational theory of interpretation may seem methodologically unauthorized. First one is representing the so-called third road in the philosophy of law and the second one is rooted in positivist tradition. Nevertheless, there are significant similarities between them that are worth emphasizing.

First of all, the derivational theory of legal interpretation is positivistic in only this sense that connects the law with activity of the lawgiver. However, this lawgiver (rational lawgiver) is a conceptual design used as a tool to put values and practices of the interpretive community into process of legal interpretation. If we look closer, it seems the derivational theory of interpretation presuposes some kind of inclusive legal positivism, which is not far from Dworkin's approach. Both Dworkin and inclusive legal positivists share the view that morality (reasoning involving values) and determining the content of law are very closely related. According to Dworkin the dependence of legal reasoning on moral considerations is an essential feature of law that derives from law's profoundly interpretative nature. Inclusive positivists treat such a dependence more as a contingent matter (it does not derive from the nature of law or of legal reasoning as such).

It is worth emphasizing that the concept of the rational lawgiver adopted by the derivational theory of interpretation is richer than just the concept of instrumental rationality. The theory assumes not only that a rational lawmaker coherently and efficiently adopts suitable means to her ends (values), but also assigns "the right values" to her (values embodied in the Constitution and accepted in Polish legal culture). In other words: the rational legislator is both-instrumentally and value rational in Weber's terms (more about values in legal interpretation see 3.7). As pointed out by Kmita [19], even just formal assumptions about rational lawgiver has ceretain moral dimension. The formal assumptions attribute coherent knowledge and asymmetric and transitive preferences to the rational lawgiver. They are some kind of intellectual tool to protect such values like the intersubjectivity of legal interpretation, predictability of court decisions, and by that-formal justice. However, those formal assumptions may not best serve such values like emancipation or communication without any constraints [19]. In any case, formal assumptions seem to reflect the essential feature of the legal practice: striving for consistent resolution of similar cases.

The important thing is that the derivational theory of legal interpretation has not been build on any particular ideology or prescriptive political philosophy (marxism, liberalism, republicanism, communitarianism, Christian social doctrine and others). The derivational theory of interpretation is rather a manifestation of "the legal point of view" with the idea of formal justice in the very center of it. This theory requires 
taking into account the political or moral values on which the given political system is based, but does not judge them in a normative and philosophical way. For this reason, it is possible to adjust the theory to various political systems as long as they respect such values as the intersubjectivity of legal interpretation, predictability of court decisions and formal justice. It is remarkable that the derivational theory of legal interpretation has emerged in times of communism and after political changes in Poland it is still influential legal theory. And this is probably because the theory tends to limit judicial authority (as well as executive) but with strong connection to the legal culture and without limiting the democratic system and broad civic participation in government.

\subsection{Is Interpretation Necessary?}

There are different views on the role of interpretation in determining the content of the law. An influential view is the one adopted by Marmor [23] and Stone [30]. According to this view it must be possible for us to grasp the meaning of legal rule in a way which does not require recourse to interpretation and interpretation is not the fundamental determinant of the meaning of linguistic expressions. According to the opposite, also influential view, interpretation is the fundamental and inescapable determinant of meaning in all cases (see for example Fish [13] and Cornell [7]). Legal rules expressed in language do not have determinate meanings and hence cannot determine their own correct application. Both views are in some sense the consequence of Wittgenstein's remarks about following the rule. If as he claims: whatever we do is, on some interpretation, in accord with the rule, then we have only interpretations or it must be possible for us to grasp the meaning of legal rule in a way which does not require recourse to interpretation. The derivational theory strongly advocates the first solution, but it does not lead skeptical conclusions from it—normative theory of legal interpretation is still possible (see Sect. 3.4.).

The theory conceives interpretation in a broad sense including both prima facie interpretive reasoning and reflective (deliberative) interpretive reasoning and interpretation is a necessary step leading from legal provisions to legal norm. A similar view is adopted by Tarello [32] and Guastini [17]. According to this view there are no rules of law without interpretation. According to the opposite view the term "interpretation" is intended to mean only deliberative interpretive reasoning (Dascal and Wróblewski [8]).

Many legal theorists treat deliberative interpretive reasoning as subsidiary to prima facie interpretive reasoning. The relationship between prima facie interpretive reasoning and deliberative (reflective) interpretive reasoning is presented as follows. Prima facie interpretive reasoning ascribes, through uncritical computation, a prima-facie meaning to the utterance at issue and deliberative interpretive reasoning intervenes: (1) when prima facie interpretive reasoning fails to provide a single, undoubted output; or (2) when multiple incompatible prima facie meanings are provided; or (3) when the prima facie meaning fails to satisfy immediately the concerns of the interpreter, so some doubts need to be addressed [18, 22]. The derivational theory holds different view. Because of the need to ensure the intersubjectivity of 
interpretation, the deliberative interpretive reasoning should always control the prima facie interpretive reasoning. The interpreter should always verify his "no doubts" state by obtaining and considering relevant interpretive factors which may not be known to him "at once".

\subsection{Is It Possible to Have a Normative Theory of Legal Interpretation?}

Raz [26] rejects the possibility of normative theories of interpretation. He doubts that it is possible to have an account in the form of a theory which purports either to operate as a recipe for concocting good interpretations, or to provide us with a general account of how to evaluate interpretations as good or bad, right or wrong. And this is for two reasons. First, because morality to which recourse must be had as regards the innovative aspect of legal interpretation is not settable by operational directives which would enable a person whose moral understanding and judgement are suspect to come to the right moral conclusions regarding situations he may face by consulting the theory. Second, because innovation defies generalisation. It makes no sense to attempt to construct a general theory which differentiates good interpretations from bad as regards the forward-looking aspect of interpretation.

Although the derivational theory does not directly answer the above-mentioned doubts, one can point to some of its assumptions that undermines those doubts. Even if morality is not settable by operational theories (and this is not obvious), it does not indicate that legal interpretive reasoning is not settable too. The derivational theory requires taking into account values (expressed in the law, e.g. in the Constitution) as one, but not the only one, among interpretive arguments. These interpretative arguments are organized into a system that enables conclusion despite some degree of ambiguity of individual arguments. It also does not seem that the innovative aspect of interpretation would exclude a normative theory of interpretation. Generalization seems to be the essence of the idea of procedural justice. Innovation always takes place against some generalization (otherwise it would not be an innovation) and if it is accepted it should become the basis for the next generalization (otherwise it remains only a deviation). In other words, normative theory should not exclude innovation, which, however, should become the basis for the next generalization.

It seems that derivational theory holds similar view as that adopted by Dworkin, who offers judges a general theory of legal interpretation which they can use to guide their interpretive activities to obtain one right answer in the case before them. However, Dworkin's general theory of interpretation is not recipe-like in the sense of providing judges with a detailed step by step programme for correct judicial decision-making. He claims that his theory is not "an algorithm for the courtroom" [9: 412]. Whereas the derivational theory postulates a detailed, holistic, sequential model of the interpretive process. Of course, this is not an algorithm in the sense of computer science (such algorithms are extremely problematic in the case of legal interpretation). It is rather an ordered collection of heuristic directives that require an interpreter's reflexive approach to their application. It can be said that the discussed theory is motivated by a "systemic" approach to legal interpretation. 
According to this approach, legal interpretation should not consist in selective, ad hoc, use of unrelated interpretative arguments, which often takes place in judicial practice.

The above-mentioned "systemic" approach is susceptible to some typical doubts. Sunstein's [31] approach to Dworkin ideas may be a good example of this. Sunstein warns against "high-level" theories which Dworkin instructs judges to construct and follow. According to Sunstein: (1) it takes too much time and may be unnecessary; (2) it may go wrong insofar as it operates without close reference to actual cases; (3) it often prevents people from getting along at all; (4) general theorizing can seem or be disrespectful insofar as it forces people to contend, unnecessarily, over their deepest and most defining moral commitments. Instead of such theory, Sunstein proposes to recognize the basic role of "incompletely theorized agreements" in judicial practice. As Sunstein points out, incompletely theorized agreements take place when judges agree on the outcomes of individual cases even though they disagree on which general theory best accounts for those outcomes.

It can be said that Sunstein's objections refer not so much to general theories as to "bad" general theories. If the theory leads to such situations as indicated in (1)-(4) then there must be something wrong with it, but that does not deprive the value of any general theory. Indeed, incompletely theorized agreements appear in the legal practice, but there are also "different theorized disagreements" (when judges don't agree on the outcomes of individual cases because they disagree on weight of interpretive arguments). In such cases, it seems necessary to refer to some general higher-level theory. According to the derivational theory, the weight of interpretative arguments should not be attributed by an interpreter in a specific case (ad hoc), but should be predetermined by normative theory.

\subsection{How Is It Possible to Have a Normative Theory of Legal Interpretation?}

In addition to the normative model of legal interpretation, the derivational theory also includes methodological reflection on how to construct such a model. That reflection is related to the basic general question that arises in normative deliberations on how to interpret the law and can be expressed as follows: on what basis can we assert that one should interpret law in one way and not the other?

In this context, the basic concept formulated by derivational theory is the concept of determinants of interpretive directives, i.e., the factors (in broad sense) which in one way or another have to be considered when formulating the directives of legal interpretation. The theory adopted the following types of determinants: conceptual and terminological apparatus; methodological criteria for the correctness of intellectual activities; theorems on the features of the legal text; theorems on the features of the legal system; theorems on the validity of specific legal norms; theorems pointing to tendencies to specific interpretive actions in the Polish legal culture; assumptions about natural language communication; assumptions about a good state and society. For example, the adoption of a certain thesis on the features of the legal text, according to which there is syntactic dismembered of norms, translates into a directive recommending the interpreter to take into account this fragmentation. 
Only the cumulative inclusion of all the indicated determinants will allow formulating the normative theory of interpretation for a specific legal culture. It must be added that simply taking into account the various determinants does not allow us to formulate a normative theory yet. The legal culture may include (and most often includes) elements incompatible with each other (e.g. incompatible views of language, culture itself, social relations, law and its application, tendencies in interpretative actions). Therefore, the culture is not an internally coherent entity, but rather a space of "attrition" of different elements. So the task of the legal terrorist is to conduct hermeneutic, constructive criticism of specific legal culture and present, as coherent as possible, a set of certain elements together with the postulate of rejection of the other elements. It is necessary to determine the relationship between the various determinants and assign them certain weights.

In other words, the mere description of a legal practice within a given legal culture is not enough as a ground for a normative theory of interpretation (because this practice may be incoherent). For example, in some judgments of Polish courts the explicit language interpretation is rejected in favor of teleological interpretation, and in some others such a possibility is excluded. On the basis of this fact, it is difficult to formulate a rule of interpretation. The description of the legal practice itself can only be a source of vague heuristic recommendations, like for example "find ordinary meaning of the word" or "take into account the purposes of the statue". The normative theory of interpretation for a given legal culture is possible only with the active, creative contribution of the theoretician who is formulating it. It is therefore always a "postulate" that can be accepted in legal practice or not. If it is accepted, it means that it is well adapted to the given legal culture.

In connection with the above remarks, it should be emphasized that the derivational theory does not imply the possibility of formulating any universal theory of interpretation that could be applied to all legal systems or legal cultures. It only assumes that a normative theory of interpretation is possible for a given legal culture or legal system.

\subsection{Intentionalism-Textualism-Purposivism-Holism}

In Anglo-Saxon legal theory arose three main, opposite to each other, approaches to legal interpretation. They are usually named as "intentionalism", "textualism" and "purposivism". They are all looking for an objective, reliable foundation for legal interpretation. The three main theories emphasize (1) the actual or presumed intent of the legislature enacting the statute (intentionalism), (2) the actual or presumed purpose of the statute (purposivism), and (3) the literal commands of the statutory text (textualism). Each of these theories was subject to intense criticism. In general, it can be said that none of the indicated interpretative sources can be an "unshakable" foundation for interpretation because in many cases they are vague and inconclusive.

It can be said that in the dispute between these theories the derivational theory supports each of the parties without advocating any of them. The discussed theory recognizes the literal (linguistic) meaning, purpose of the statue and intent of the 
legislature as the interpretative arguments, however, none of them is treated as irrefutable. The theory assigns different weight to these arguments in different circumstances. It seems that the derivational theory is similar to "holistic" and "dynamic" approaches like one developed by Eskridge and Frickey [11]. They tried to avoid the flaws of each of the three "main" theories. According to this approach, the Court considers a broad range of textual, historical, and evolutive evidence when it interprets statutes. However, this approach is a kind of descriptive theory seeks to make sense out of the Court's practice in statutory interpretation (in few famous cases). Nevertheless, this approach allows to outline (though very sketchy) the relationship (hierarchy) between different types of interpretive arguments. Generally speaking, this relationship is perceived as a "funnel of abstraction". This funnel organizes interpretative sources according to the level of abstraction. As inquiry moves from most concrete to most abstract, interpreter will move from statutory text through legislative purpose and history to current policy and evolution of the statue. "For example, in formulating her preunderstanding of the statute and in testing it, the interpreter will value more highly a good argument based on the statutory text than a conflicting and equally strong argument based upon the statutory purpose" [11: 353].

The derivational theory adopts a similar hierarchy of interpretative sources, however, more elaborate in details (more "procedural"). Textual (linguistic) arguments should always be the starting point, but should always be verified by reference to non-linguistic arguments (value being purpose of the statue and other values attributed to the rational legislator). Although linguistic arguments are very strong, in certain circumstances (and to some extent) may be undermine by non-linguistic arguments. According to the derivational theory, the great strenght of linguistic arguments does not come from the language itself. This strength is the result of the importance of values realized by reference to linguistic meaning (such as relative stability and clarity of law's content and predictability of judicial decisions). The derivational theory assumes that in a good state authority does not limit these values without a particularly important reason (higher-weighted values). Macagno et al. [22] tried to identify levels of presumptions in legal interpretation. According to them, the basic level is the pragmatic level that includes the purpose of the law (like "the law needs to be understood; "the law can not be unjust or meaningless", etc.). If we agree that the purposes of law are certain values, then we can say that legal interpretation is (at its foundation) always a matter of values. Holistic approach to legal interpretation allows for taking into account different values and resolving conflicts between them.

\subsection{Literalism-Contextualism, Structuralism-Nominalism}

One of the determinants of interpretive directives in derivational theory are assumptions about natural language communication (see Sect. 3.5) answering the question: how actually this language works?

Obviously, there are variety of answers to mentioned question in linguistics and philosophy of language. This is a solution worth emphasizing that derivational 
theory adopts certain view not because it is entirely true for all language communication, but it seems to serve as the best tool in obtaining the intersubjectivity of legal interpretation (see Sect. 3.7). We can call this view "moderate contextualism" or "weak structuralism".

According to this view, semantic convention is not enough to fully determine meaning of the utterance (stopping on literal meaning can not complete the interpretation). The meaning of any token-sentence is always determined by pragmatic factors within the specific context of utterance. However, semantically fixed meanings exist and they set out some of the possible interpretations. In some cases there are sub-sentential expressions that have "indefeasible" semantic meaning which is not dependent on the occasions of utterance and designates an impassable semantic limit of interpretation. For example, we can acknowledge (if we have good contextual reasons) that in the provision prohibiting motor vehicles from entering the park, the expression "motor vehicles" means "motor vehicles not being ambulances". But it can not be assumed that in the provision imposing a fine of one thousand dollars, the expression "a thousand" means "ten thousand" (even if we have grate contextual reasons, e.g. the fine is disproportionately low in relation to the offense).

The existence of semantically fixed conventional meaning for any tokenexpression is denied by radical contextualism (Recanati [29]; on contextualism and legal interpretation see Chiassoni [4]). Even though the vision of radical contextualism seems quite tempting in everyday communication, in the case of legal interpretation it can lead to unacceptable consequences. It seems that in the case of legal interpretation the idea of a pre-existing, semantically fixed meaning have some kind of axiological importance.

The approach to language accepted by derivational theory can also be called "weak structuralism". According to this approach there is distinction between the semantic language system and the language practice. The system should be playing some kind of normative role against the language practice (by restraining it in some kind of way). The context is ubiquitous and necessary to understand the expression but the systemic (syntactic-semantic) meaning limits in some way possible ways of understanding the utterance. According to the opposing view (let's call it "the nominalist view"), there is no abstract language system that underlines specific speech acts. There is no abstract language system and the language is basically nothing more than a practice of using language utterances. Therefore the language system can not play normative role against the language practice and syntactic-semantic meaning should not limit ways of understanding the utterance. If there are any limits in interpreting, they are not based on syntactic or semantic rules, but rather on contingent facts accompanying language communication. We can say that a nominalist view is at the root of many philosophical approaches to language like Rorty's neopragmatism or Recanati's radical contextualism. Such a view of language may seem convincing in the case of everyday conversation or interpretation in literature and poetry, however, in the context of legal interpretation it reduces the possibilities of obtaining an intersubjective result and causes consequences that are difficult to accept (as indicated above in the case of radical contextualism). 


\subsection{What Value is Behind All of This? Values and Interpretation}

As it was indicated in Sect. 3.5, it seems that legal interpretation at its foundation is always a matter of values. In the case of derivational theory the significance of values manifests itself on two levels. The first level is related to the determinants of the interpretative directives and way of formulating the content of interpretative directives (we can call it "meta-level"). The second one (we can call it "substantiallevel") is related to the fact that directives require the interpreter to take values into account when interpreting.

At the meta-level, it is important what value interpretative directives are to serve. It seems that the fundamental value behind the normative model of interpretation formulated by derivational theory is the intersubjectivity of legal interpretation. In other words: the most important determinants of the interpretative directives are methodological criteria for intellectual activities, and among them, the greatest importance is attached to the postulate of intersubjective justification and controllability of intellectual activities that constitute the legal interpretation (and consequently also the result of interpretation). Because the intersubjectivity in some way requires conclusiveness, the normative model of interpretation is designed to obtain a conclusive result (to the maximum possible extent).

The conclusiveness is easy to achieve when all the interpretive sources point in the same direction. However, in hard cases they point to different directions. When, at the same time, the structure of the legal text, linguistic arguments, systemic arguments, previous judicial decisions, legislative history, purpose and other values of the statue, are not conclusive, it is extremely difficult to obtain an intersubjectively valid result. In order to ensure the conclusiveness of the interpretive process in such cases, it is necessary to adopt some additional rules which will allow to end the interpretive discourse. The derivational theory postulates reliance on certain interpretive presumption. In short, in accordance with this presumption in a situation of extreme inconclusiveness, we should adopt this interpretative alternative that least limits the space of freedom-in dubio pro libertate. This rule has an axiological justification based on a specific assumption about a good state and society. According to this assumption, in a good state, public authority does not limit freedom without clear reasons. In a good state, public authority is responsible for the clarity of the content of the law. The law always limits the area of freedom in some way. In a good state, these borders should be relatively clear. Therefore, when law is extremely unclear and prevents the conclusiveness of interpretation, we should not accept an alternative which limits freedom. Of course, the weight of this rule is culturally relativised. It fits Polish legal culture (many judicial decisions have manifested similar approaches). However, in a completely different culture, it may not be justified.

At the substantial-level, it is significant that the derivational theory in each case requires the interpreter to reconstruct the global (all-things-considered) assessment (axiological judgement) attributed to the rational lawgiver. The reconstruction and the use of global assessment takes place during the so-called "functional interpretation" and is based on basic theoretical assumption called "the assumption of isomorphism between global assessment and norm". It can be expressed as follows: the content of the specified norm (rule) $\mathrm{N}$ (order/prohibition, identification of the 
addressee, description of the circumstances, description of the action) corresponds to the content of a particular global assessment GA [including a specific value being purpose " $\mathrm{C}$ " and other values "W(1)-W(n)" being implemented to appropriate degrees]. The final goal of the functional interpretation is to reconstruct such a pair as-the global assessment and the corresponding norm (rule) which should be attributed to a rational lawgiver. It can be said that a certain global assessment (and thus the content of a certain norm) is the result of settling conflicts between the purpose of norm and other values.

The interpretive structure is the starting point of a functional interpretation, creating a specific "space" in which the interpreter moves. The interpretive structure is made up of all interpretive options that are possible in the light of the linguistic interpretation directives. When reconstructing the global assessment, it is of utmost importance to determine whether within the framework of the interpretative structure an inconsistency occurs between any of the other values identified by the interpreter and the value being the purpose of norm, and therefore-whether the adoption of an interpretative option most fulfilling the purpose of norm, does not reduce the degree of realization of that other value to unacceptable level. The inconsistencies in values should be resolved by interpreter, based on systemic orders of global assessments that are reproducible on the basis of a legal text, statements of jurisprudence and judicial decisions, as well as legislative documents. Systematic orderings of global assessments determine the ranking of global assessments from the point of view of the extent to which one value is realized while reducing the realization of the other (in particular, they define unacceptable levels of violation of certain values). Thanks to the systemic ordering of global assessments, the states of affairs which are a definite degree of good or evil in the light of particular values obtain a "new" qualification as a definite degree of good or evil from the point of view of the entire system of values (all-things-considered).

The "systemic" approach to values outlined above is exposed to some typical doubts. Good example may be Finnis's [12] doubts about Dworkin's idea of the one right answer. Finnis argues that while we should seek good answers and avoid bad ones, we should not delude ourselves into dreaming of uniquely correct answers to issues of legal interpretation-to do so commits us to utilitarianism's deepest and most flawed assumption: the assumption of the commensurability of basic goods. Finnis argues that it is not possible for legal interpretation to lead judges to one right answer, because of pervasive incommensurabilities in the criteria by reference to which we are supposed to adjudge one interpretation to be better than another.

The incommensurability of values is the subject of a vast discussion which is difficult to present. There are different conceptions of value incommensurability. It seems that relevant from discussed point of view is the conception according to which values are incommensurable if there is no true general overall ranking of the realization of one value against the realization of the other value. Two values are incommensurable if there is no general way in which A and B trade off in the whole range of situations of choice and comparison in which they figure [33: 59]. At first look, it seems that the assumption of a systemic ordering of lawgiver's global assessments rules out this kind of incommensurability. But it depends on how we understand "the true general overall ranking" (in what sense it should be "true"?). 
Indeed, it seems very doubtful that for every community or person we can identify such a pre-existing general overall ranking. Nevertheless, acting entities (in particular state authorities) making specific decisions in some way hierarchize the conflicting values and often try to do it in a coherent way (they are making "commensurable from what's incommensurable" through decisions). Even if there is no universally valid general way to resolve any given conflict of values, there may be some value in virtue of which the realization of one value ranks against realization of the other. For example, Chang [3] argues that there are "nameless values" which combine values in a way that allows for the comparability of alternatives in virtue of these nameless values. Systemic order of global assessments containing specific values can be seen as such nameless values. Recognizing the existence of such nameless values can be called "weak commensurability" and it does not rule out by itself incommensurability in the sense indicated above.

\section{Summary. The "Hard Core" of the Theory}

Trying to make an overall evaluation of the derivational theory one can say that it has two levels (or aspects): local and universal. Undoubtedly, the derivational theory was designed for the Polish legal system and legal culture. This creates its local level. However, beyond its local features, the derivational theory is presenting some significant universal ideas about legal interpretation. This creates universal level that we can call the "hard core" of the theory.

The local level of theory is related to the fact that it takes into account the features of Polish legal texts and features of the Polish legal system, the way of lawmaking in Poland, the principles of law and Polish judicial practice as well as assumptions about good state and society adapted to Polish legal culture. This means that the theory in all extend can not be simply and directly applied to any other legal system or legal culture. It needs to be emphasizing that legal system in Poland evolved from totalitarian (communism) legal system to legal system of contemporary liberal democracy based on the Montesquieu's separation of powers principle. Now this is so-called closed system of the sources of law (only sources indicated in the Constitution) with courts authorized only to apply the law. Generally speaking, the Polish legal system is based on the model of continental legal system (civil law tradition) with strong German and French historical influences.

However, there is also universal content of the derivational theory. This "hard core" contains some basic features and assumptions that can be the foundation for different derivational theories for different legal cultures and systems. We can say that this is the "hard core" of a theory in a sense given by Lakatos [20], that is key theoretical assumptions and claims that constitute the very core of the theory. Those principal assumptions and claims cannot be abandoned by a theoretician if she wants to work in the "derivational paradigm". Let's try to point out the elements of this "hard core".

(I) Undoubtedly, the most important element of the "hard core" is the very definition of legal interpretation. The legal interpretation is not just about determining the meaning of a phrase contained in the legal text (although most theories 
focus only on this aspect). The derivational theory perceives interpretation as a process of moving from sentences of a legal text (provisions) to a sufficiently unambiguous legal norm that has a definite syntactic structure (order/prohibition, identification of the addressee, description of the circumstances, description of the action). This allows to take into account the whole "syntactic" aspect of legal interpretation. In other words, this definition of interpretation allows us to analyze how the various provisions participate in determining the content of individual syntactic elements of the norm. Thanks to this, it is possible to describe such phenomena as condensation and dismemberment of elements of the norm in the provisions (see analyses of the EU legal texts from this perspective in [16]). It can be added that such a definition of interpretation can also be used to modeling the interpretation of case law. In this case, however, provisions (sentences of the legal text) would have to be replaced by sentences contained in court judgments.

(II) The concept of a rational lawgiver should also be considered to be an element of a "hard core". The assumption that the law is created by an idealized person who is instrumentally rational and has all necessary knowledge, and is also guided by a coherent order of global assessments (all-things-considered judgements), underlies the entire normative model of interpretation.

(III) The "hard core" also contains rest of the conceptual and terminological apparatus adopted by the theory. Such crucial concepts as the framework provision, supplementary provisions, modifying provisions, functional interpretation, global assessment, determinants of interpretative directives, and others, are closely tied to the theory and serve to formulate its essential foundations.

(III) It seems that the heuristics of creating a normative theory of interpretation also belong to the "hard core". In general, it requires the theoretician to identify the determinants of the interpretative directives appropriate for a given legal culture and legal system. Next, he must assign them a certain weight and associate them with certain aspects of the interpretation process. However, the basic heuristic directive should be regarded as the directive, according to which determinants and their weight should be selected so that the normative model ensures (as much as possible) the intersubjectivity and conclusiveness of legal interpretation. In other words: intersubjectivity and conclusiveness are the goals of normative legal interpretation model. In order to achieve these goals, the normative model should be designed as procedural and holistic, requiring consideration of various interpretative arguments, and in the case of extreme inconclusiveness adopt some interpretative presumptions.

(IV) Moderate contextualism should also be considered as a component of the "hard core". The assumption that in each case the interpreter must take into account the linguistic and extra-linguistic context of the expression seems to be extremely important for the derivational theory. The manifestation of this is the recognition of the principle of omnia sunt interpretanda as the basic principle of interpretation. In addition, the assumption of moderate contextualism justifies the relation between the linguistic and extra-linguistic aspect of interpretation (systemic and functional). According to the derivational theory, the interpretation ends after the application of linguistic, systemic and functional directives [38]. The necessity of taking into account the non-linguistic context does not mean, however, that it can freely modify 
the semantic-syntactic meaning of the expression (there are some semantic limits of interpretation).

The "hard core" of derivational theory characterized above presents a certain universal way of thinking about the interpretation of law (though of course not the only one possible). It seems that based on it you can build many normative theories for different legal systems. Despite the fact that these theories would have to differ to some extent, all could be called "derivational" ones.

Open Access This article is distributed under the terms of the Creative Commons Attribution 4.0 International License (http://creativecommons.org/licenses/by/4.0/), which permits unrestricted use, distribution, and reproduction in any medium, provided you give appropriate credit to the original author(s) and the source, provide a link to the Creative Commons license, and indicate if changes were made.

\section{References}

1. Bogucki, Olgierd. 2016. Model wyktadni funkcjonalnej w derywacyjnej koncepcji wyktadni prawa (Model of Functional Interpretation in the Derivational Theory of Legal Interpretation). Szczecin: Polgres.

2. Bork, Robert H. 1990. The Tempting of America. New York: Free Press.

3. Chang, Ruth. 2004. All Things Considered. Philosophical Perspectives 18(1): 1-22.

4. Chiassoni, Pierluigi. 2006. A Nice Derangement of Literal-Meaning Freaks: Linguistic Contextualism and the Theory of Legal Interpretation. In Analisi e diritto 2005. Ricerche di giurisprudenza analitica (Analysis and Law 2005. Research of Analytical Jurisprudence), ed. Paolo Comanducci and Ricardo Guastini, 115-126. Torino: Giappichelli.

5. Choduń, Agnieszka. 2010. Lex specialis i lex generalis a przepisy modyfikujące (Lex Specialis, Lex Generalis and Modifying Provisions). In W poszukiwaniu dobra wspólnego. Księga jubileuszowa Profesora Macieja Zielińskiego (Looking for a Common Good. Jubilee Book of Professor Maciej Zieliński), ed. Agnieszka Choduń and Stanisław Czepita, 215-225. Szczecin: Wydawnictwo Naukowe Uniwersytetu Szczecińskiego.

6. Choduń, Agnieszka. 2018. Aspekty językowe derywacyjnej koncepcji wyktadni prawa (Linguistic Aspects of the Derivational Concept of Legal Interpretation). Szczecin: Wydawnictwo Naukowe Uniwersytetu Szczecińskiego.

7. Cornell, Drucilla. 1992. The Philosophy of the Limit. New York: Routledge \& Kegan Paul.

8. Dascal, Marcelo, and Jerzy Wróblewski. 1988. Transparency and Doubt: Understanding and Interpretation in Pragmatics and in Law. Law and Philosophy 7(2): 203-224.

9. Dworkin, Ronald. 1986. Law's Empire. London: Fontana Press.

10. Endicott, Timothy A.O. 1994. Putting Interpretation in Its Place. Law and Philosophy 13: 451-479.

11. Eskridge, William N., and Philip J. Frickey. 1990. Statutory Interpretation as Practical Reasoning Statutory Interpretation as Practical Reasoning. Stanford Law Review 42: 321-384.

12. Finnis, John. 1987. On Reason and Authority in Law's Empire. Law and Philosophy 6: 357-380.

13. Fish, Stanley. 1989. Doing What Comes Naturally: Change, Rhetoric and the Practice of Theory in Literary and Legal Studies. Durham and London: Duke University Press.

14. Fiss, Owen M. 1982. Objectivity and Interpretation. Stanford Law Review 34: 739-763.

15. Godek, Andżelika. 2011. Zastosowanie derywacyjnej koncepcji wykładni prawa do rozstrzygania spraw ze stosowaniem przepisów unijnych (Application of the Derivative Concept of Legal Interpretation in Resolving Matters Involving Elements of EU Law). Ruch Prawniczy. Ekonomiczny $i$ Socjologiczny (Journal of Law, Economics and Sociology) 1: 21-40.

16. Godek, Andżelika. 2015. On Legal Situations and the Interpretation of European Union law. Studia Prawa Publicznego (Studies in Public Law) 2: 35-56.

17. Guastini, Riccardo. 2011. Interpretare E Argomentare (To Interpret and Argue). Milano: Giuffrè.

18. Kennedy, Duncan. 2007. A Left Phenomenological Critique of the Hart/Kelsen Theory of Legal Interpretation'. Kritische Justiz 40(3): 296-305. 
19. Kmita, Jerzy. 1990. Etyczny aspekt koncepcji racjonalnego prawodawcy (Ethical Aspect of the Concept of Rational Lawgiver). In Szkice z teorii prawa i szczegółowych nauk prawnych (Sketches from the Theory of Law and Legal Dogmatics), ed. Sławomira Wronkowska and Maciej Zieliński, 413429. Poznań: Wydawnictwo Naukowe Uniwersytetu Adama Mickiewicza.

20. Lakatos, Imre. 1970. Falsification and the Methodology of Scientific Research Programmes. In Criticism and the Growth of Knowledge, ed. Imre Lakatos and Alan Musgrave, 91-196. Cambridge: Cambridge University Press.

21. Levinson, Sanford. 1982. Law as Literature. Texas Law Review 60(3): 373-402.

22. Macagno, Fabrizio, Douglas Walton, and Giovanni Sartor. 2018. Pragmatic Maxims and Presumptions in Legal Interpretation. Law and Philosophy 37: 69-115.

23. Marmor, Andrei. 2005. Interpretation and Legal Theory. 2nd ed. Oxford: Hart Publishing.

24. Morawski, Lech. 2006. Zasady wykładni prawa (Principles of Legal Interpretation). Toruń: Dom Organizatora.

25. Płeszka, Krzysztof. 2010. Wykładnia rozszerzajaca (Extensive Interpretation). Warszawa: C.H. Beck.

26. Raz, Joseph. 1996. On the Nature of Law. Archive fur Rechts und Sozialphilosophie 82: 1-25.

27. Raz, Joseph. 1996. Why Interpret? Ratio Juris 9(4): 349-363.

28. Raz, Joseph. 1996. Intention in Interpretation. In The Autonomy of Law, ed. Robert P. George, 249286. Oxford: Clarendon Press.

29. Recanati, Francois. 2004. Literal Meaning. Cambridge: Cambridge University Press.

30. Stone, Martin. 1995. Focusing the Law: What Legal Interpretation is Not. In Law and Interpretation, ed. Andrei Marmor, 31-96. Oxford: Clarendon Press.

31. Sunstein, Cass R. 1996. Legal Reasoning and Political Conflict. Oxford: Oxford University Press.

32. Tarello, Giovanni. 1980. L'interpretazione Della Legge (Interpretation of the Law). Milano: Giuffrè.

33. Wiggins, David. 1997. Incommensurability: Four Proposals. In Incommensurability, Incomparability, and Practical Reason, ed. Ruth Chang, 52-66. Cambridge: Harvard University Press.

34. Wróblewski, Jerzy. 1990. Rozumienie prawa i jego wykładnia (Understanding of the Law and Its Interpretation). Wrocław: Ossolineum.

35. Zieliński, Maciej. 1972. Interpretacja jako proces dekodowania tekstu prawnego (Interpretation as a Process of Decoding Legal Text). Poznań: Wydawnictwo Naukowe Uniwersytetu Adama Mickiewicza.

36. Zieliński, Maciej. 1987. Decoding Legal Text. In Polish Contributions to the Theory and Philosophy of Law, ed. Zygmunt Ziembiński, 165-178. Amsterdam: Rodopi.

37. Zieliński, Maciej. 2002. Wykładnia prawa. Zasady, reguły, wskazówki (Legal Interpretation. Principles, Rules, Hints). Warszawa: LexisNexis.

38. Zieliński, Maciej. 2012. Wykładnia prawa. Zasady, reguły, wskazówki, (Legal Interpretation. Principles, Rules, Hints). 6th ed. Warszawa: LexisNexis.

39. Ziembiński, Zygmunt. 1960. Przepis prawny a norma prawna (Legal Provision and Legal Norm). Ruch Prawniczy. Ekonomiczny i Socjologiczny (Journal of Law, Economics and Sociology) 1: 105-122.

40. Zirk-Sadowski, Marek. 2012. Pojęcie, koncepcje i przebieg wykładni prawa administracyjnego (Concept, Conceptions and Course of the Interpretation of Administrative Law). In System prawa administracyjnego, t. 4, Wykładnia w prawie administracyjnym (System of Administrative Law, vol. 4, Interpretation of Administrative Law, vol. 4, ed. Leszek Leszczyński, 156-159. Warszawa: C.H. Beck.

Publisher's Note Springer Nature remains neutral with regard to jurisdictional claims in published maps and institutional affiliations. 